Article

\title{
THE RISKY-OPPORTUNITY ANALYSIS METHOD (ROAM) TO SUPPORT RISK-BASED DECISIONS IN A CASE-STUDY OF CRITICAL INFRASTRUCTURE DIGITIZATION
}

\author{
Ali Aghazadeh Ardebili ${ }^{1, \dagger, \ddagger, *} \mathbb{D}$, Elio Padoano ${ }^{2, \ddagger, *}$, Antonella Longo and Antonio Ficarella $\mathbb{D} 1, \ddagger$ \\ 1 SyDa Lab, CRISR Center, Department of Engineering for Innovation, University of Salento, LECCE (LE),73100, \\ Italy. \\ 2 Department of Engineering and Architecture, University of Trieste \\ Trieste (TS), 34100, Italy. \\ * Correspondence: ali.a.ardebili@unisalento.it; padoano@units.it \\ $\dagger$ Affiliation Change: The affiliation of this author when current research started (2019) was the University of Trieste, \\ on December 2020 his affiliation is changed to the University of Salento \\ ‡ Ali Aghazadeh Ardebili and Elio Padoano have participated in (a) conception and design, analysis and interpretation \\ of the data; (b) drafting the article or revising it critically for important intellectual content; and all authors \\ participated in (c) proof reading and refining the final version.
}

\begin{abstract}
Socio-ecologic, socio-economic, and socio-technical transitions are opportunities that require fundamental changes in the system. These will encounter matters associated with security, service adoption by end-users, infrastructure and availability. The purpose of this study is to examine and overcome the risks to take advantage of opportunities through the novel Risky-Opportunity Analysis Method (ROAM). A novel quantitative method is designed to determine when, after making some changes, the risks become acceptable so that the opportunity does not deviate from the objectives. The approach provided a quantitative evaluation of the possible changes in parallel with digitization, towards providing a green Service Supply Chain (SSC). The result of ROAM shows that the most cost-effective change to increase the resilience of the system is a solution (SMS) which is different from that identified by a TOPSIS multi-criteria method. Real-word decisions in change management should tackle the complexity of systems and uncertainty of events during and after transition through a careful analysis of the alternatives. A case-study was carried out to evaluate the alternatives of an ancillary service in the Payment Service Providers (PSP). The comparison of the ROAM results with the traditional TOPSIS of the case-study unveils the priority of the ROAM in practice when the alternatives are Risky-Opportunities. The existing risk assessment tools do not take advantage of risky opportunities. To this aim, the current article introduces the term Risky-Opportunity, and two indexes Stress and Strain of the alternatives that are designed to be employed in the new quantitative ROAM approach.
\end{abstract}

Keywords: Resilience; Risky-Opportunity Analysis Method (ROAM); Socio-Ecological Transition; SocioTechnical Transition; Cyber-Physic-Social Systems; Change Management; Risk Management; Critical Infrastructure Resilience; Critical Entities Digitization; Risky-Opportunity (RO); Payment Service Providers (PSP); Stress, Strain

\section{Introduction}

Innovation and change are the foundations of sustainable development and contribute to creating a resilient future. To this aim, it is crucial to consider a risk-based approach to carry out transformation in real-world complex systems Holton (2020); Waddock et al. (2015). The scope of this study is Critical Infrastructures (CI) and their role in the transformation of complex systems. Digitization of CI is a hot trend that bonds society with technology Holton (2020); Pidgeon (2020); Stasik and Jemielniak (2021) and leads to the transformation of complex systems into Cyber-Physic-Social Systems (CPSS). However, as CIs provide a vital service to society, their transformation needs responsible involvement Glerup and Horst (2014): the changes should not interfere with service continuity of CIs, but new ways of delivering services should be accepted by society Gravesteijn and Wilderom (2018). Payment Service Providers (PSP) are CPSS that 
can be considered both as a critical entity of society and pioneers of digitization. However, such transformation is a risky process, and the complexity of CPSS escalates the uncertainty and risks respectively Pidgeon (2014); Schweizer (2019).

Digitization is a sustainable solutions for the future that aims to exploit opportunities behind automation of system, but it needs some changes in the main service or its ancillary services; these changes are associated with risks concurrently Johannes and Sijm (2021). There is a gap in transformation studies of critical and complex service systems. Extensive research has been focused on risks in the production sector, while far fewer studies have investigated the transition to risk-free services Asenova et al. (2011). Socio-ecological, socio-economic, and socio-technical transformation Bechtold et al. (2017); Hietala and Geysmans (2020); Jean-Jules and Vicente ( 2020 ) is essential to produce a systematic change towards the concept of sustainable service. This was the main motive of carrying out the case study on a critical entity.

E-Payment has been considered a traditional complimentary service in financial systems which is provided by PSP companies. This service creates hazardous waste in the service supply chain of PSP companies through payment receipts. Thermal papers, which are widely used in the e-Payment service as receipts, are indeed toxic Ehrlich et al. (2014) because they contain non negligible quantities of reactant acid (usually bisphenol A - BPA) Braun et al. (2009); Ullah et al. (2018); Vandenberg et al. (2007); Zhou et al. (2019). Thermal paper is not only a cause of health issues, but it must also be recycled separately from other papers. Therefore, a change in the way this service is provided is necessary for PSP companies to move towards green service.

The main objective of this research project is to design a novel quantitative method to determine when, after making some changes, the risks become acceptable, so that the opportunity does not deviate from the objectives. With this aim, the ROAM approach is proposed, and the objective of the case study is to carry out a multi-dimensional analysis employing ROAM in order to find the most effective way for a transition towards sustainable service in PSP companies.

Indeed, different solutions to eliminate, reduce, or manage the waste in the life cycle of thermal papers are possible. Nevertheless, different methods provide different ecological and economic benefits, but they are also associated with some risks and resource requirements to enable the change in the company's activity and processes. Resource allocation is crucial when the available resource are limited Chen and Dong (2018). The Risky-Opportunity Analysis Method (ROAM), based on an Analytic Network Process model, compares the resource consumption and assesses risks for substituting the existing receipting system with an eco-friendly one. The outcome of this method is the most feasible way of introducing a change in the PSP for its transition towards sustainability Dos Santos Paulino (2009).

\subsection{Resilient and sustainability of PSP service supply chain}

The electronic payment service is a developed digitalized sector of e-commerce that enact online payment methods Andersen et al. (2004); Eduardsen (2018); Goel and Venkat Narayana Rao (2019). Notwithstanding, the security and reliability risks are evident in e-commerce Rehman et al. (2012); Salama et al. (2011); yet, this service provider aims to facilitate e-payment through providing digital transactions methods instead of cash payment Rajesh et al. (2017). Due to the nature of this service, the payment service provider (PSP) employs outsourced suppliers for a part of the required ancillary service such as telecommunication service providers, internet service provider Choi et al. (2006); Ma (2013).

PSP perform other activities like providing POS-terminals for intermediary role players such as shop owners, and documenting the transactions by printing a receipt at the payment point. In a nutshell, the payment service providers along with third parties, end users and intermediary role players inaugurate a network of cyber-physic-social system within the e-payment supply chain.

The final users of this service are the whole nation in the country, therefore this sector is vital for society and needs a social engagement too El Bassiouny et al. (2018); Gravesteijn and Wilderom (2018). This means that the PSP is a critical entity and the study of resilient and sustainable functioning of this 'system of systems' is crucial. In this article we adopt a process perspective Azapagic (2003 2010). Since PSP is a service-based business Pallaro et al. (2017), the aim is to devise a more sustainable process by specifically focusing on an ancillary service of 
the system, which is providing payment receipts. This service can be investigated as an instance of supply chain.

The investigation of resilience of a service supply chain has started on 2002, and have been focused on redundancy and reserving a part of the available resources of the enterprise to be utilized after a disruption Sheffi and Rice Jr. (2005). Indeed, most of the studies about the resilience of the supply chain have explored disruption risks Blos et al. (2010); Ji and Zhu (2008), logistics Karimi (2009); Wang and Ip (2009) and security Engelhard and Böhm (2013); Weber ( 2010) until 2014, when Winston (2014) raised the issue of resilience and climate change. After that, the resilience of service providers and the environmental pillar of sustainable development have been common research topics Paterson et al. (2014).

Even if many studies have had the core services as investigation targets, some have been focused on ancillary services. For instance, in 2017 a case study of a cement factory focused on ancillary services of the cement producer and studied the service resilience with environmental aspects and considered green supply chain as a factor of resilience in competitive international markets Jamali et al. (2017). In all of the above mentioned studies, emission and climate change were key points of resilience and sustainability of the service supply chain. The present paper investigates the opportunity to make a service supply chain (i.e. PSP) more resilient Arva et al. (2020) by changing the way in which one ancillary service (printing the receipt using thermal paper, a toxic solid waste - Akilarasan et al. (2018)) is presently performed. This transition must consider the risks of substituting the old ancillary service with a resilient one, the possibility to improve the risk-taking capability of the supply chain, and the resources required to make the transition. In the next subsection the research on risk assessment and resource consumption in risky transitions will be summarized.

\subsection{Risk and Resource Consumption Evolution in the Literature}

In the introduction, risky-opportunities were defined and a new method was suggested as a solution that offers a different view on opportunity management and resource allocation. A survey of the literature has been conducted and the results prove the importance of carrying out an investigation on risky opportunities and resource allocation, as studies on these are currently lacking.

Hetrick (1969) stressed the need for a screening definition of an opportunity; he used the Monte Carlo method and the balancing of risk on different projects. Some studies emphasize the need to use the positive effects of uncertainty, and there are case studies which focused on opportunity management besides the risks Peker et al. (2016); Saaty (2015); Wiratanaya et al. (2015). In particular, Hillson (2003); Ivascu and Cioca (2014); Olsson (2007) investigated the kinds of opportunities associated with different levels of threats that could provide an advantage to companies or projects.

'Risk-taking' is not a new concept. Research on risk-taking started in 1944 in a study on proportional income taxation Domar and Musgrave (1944), then in 1965 on individual risk-taking Lefcourt (1965), and in 1970 group risk-taking was studied by other researchers Teger et al. ( 1970). At the personal level, one who believes he is competent in making decisions tends to see more opportunities in future uncertainty than threats Krueger Jr and Dickson (1994). However, at the management level, it is necessary to consider both sides; so an effective project manager needs to effectively manage risks while taking into account both threats and opportunities Steed (2000), and, in general, the management of uncertainty for projects should include risk management and opportunity management Ward and Chapman (2008).

At the project level, the objectives should be protected from any deviation caused by the negative effects of a future risk. This mitigation will be the result of specific measures implemented in advance. Therefore, some resources should be assigned to put the measures in place. In light of the existing literature, resource allocation is of paramount importance for risk acceptance. From a decision making viewpoint resource allocation is a very important step of a structured decision-making process.

The first research on resource allocation decisions in risky environments was conducted at Victoria Hospital in 1975 and published in 1979 Kirudja (1978). Nowadays, resource allocation 
analysis is more popular and it is discussed in studies on uncertainty and risk management, such as in risk-based surveillance Alban et al. (2020), resilience-based studies Lenjani et al. (2020), safety Vamvakas et al. (2019), healthcare Grant et al. (2019) and others. The two most-cited articles which consider resource consumption in risky environments are in the cloud-computing subject area Buyya et al. (2008 2009). All these papers confirm the significance of resource consumption planning in risk management.

From a risk management methodological point of view, one of the most important methods supporting the analysis of opportunities and threats, is the Benefits, Opportunities, Costs and Risks (BOCR) approach Saaty (2001). Projects are evaluated from all aspects: risks, opportunities, costs and benefits, by means of the Analytic Network Process (ANP) to select the best project or portfolio Mohammadi et al. (2015); Tchangani (2015); Wijnmalen (2007). This approach is criticized by some scholars. For instance, the ratio $\frac{B}{C \cdot R}$ is criticized because some researchers believe that 'the product of costs and risks is not meaningful' Millet and Wedley (2002) or 'opportunity and risk priorities could be regarded as probabilities' Wijnmalen (2007). However, in practice, pairwise comparisons are done with respect to importance, preference or likelihood, so the priority vectors derived from them are for Importance, Preference, or Likelihood. The concept of 'likelihood' is very similar to that of 'probability'. Wijnmalen's point was that opportunity and risk refer both to the future, and we are on much shakier ground when making judgments and deriving priorities there.

Resource allocation can be performed effectively if it is supported by a quantitative evaluation. Several Multi-Criteria Decision-Making (MCDM) tools have been employed to this end Li et al. (2016); Saaty (2008); Saaty and Peniwati (2013); Tulasi and Rao (2015). The method proposed here is also a MCDM method that can be used to evaluate the risk-taking capability of a company, with the aim of accepting a certain level of risk to seize an opportunity and at the same time specify the quantity of resources needed to seize the RO at the project level. In the following sections, the methodology will be illustrated.

\section{Materials and Methods}

\subsection{Materials}

Aghazadeh Ardebili (2020); Aghazadeh Ardebili et al. (2019 2020) investigated the service supply chain of a PSP company. In those papers, the Technique for Order of Preference by Similarity to Ideal Solution (TOPSIS) was used to prioritize the alternative solutions; in the current study the same alternatives will be assessed through the ROAM approach; the final results will be compared with the results obtained from the traditional analysis of the alternatives that does not consider the ROs and risk acceptance. The data for the comparison matrix were collected through semi-structured interviews with four group of technical staffs including hardware and software developers, which have experience of working in PSP sector, along with R\&D experts and Data analysts.

\subsection{Supporting software tools}

The decision support tool Super Decisions V3.2 is used for the Analytic Network Process analysis. Figures 3 and 4, and Table 3 were produced by means of this software. The tool can be used to implement Analytic Hierarchy Process (AHP) and ANP models for combining judgment and data to effectively rank options and predict outcomes.

\subsection{Terminology and Definitions}

This section aims to clarify the key terminology.

\section{Risky-Opportunity (RO)}

First of all, it should be reaffirmed that some of the terms used here, such as 'project', 'risk management' and 'risk management plan', are accepted definitions in the literature. However, 'risky-opportunity' (RO), which is used in this paper, does not mean an uncertain event with pure threats or an uncertain event with pure opportunities. ROs are future uncertain events that can have both positive and negative effects on the project objectives at the same time. 
Main and Secondary Goals

In project management the word 'outcome' signifies the results of a work-package. The final outcomes are the deliverables of the project. Objectives and requirements are necessary to assess the quality of an outcome. For example, the outcome of the digitalization project is a service that passed all the service quality requirements and it is ready for functioning. The term 'goal' in this study is used in two ways. There are two kinds of goals for a new risk management plan. The main goal is achieving the best outcomes for the project. All of the activities are planned and undertaken for this reason. In general, a risk management plan is followed to control future uncertain events so there will not be any deviation from the main goals. The secondary goals include achieving the objectives of the decision maker even if it means going ahead with an RO and accepting the risks it may bring to the main project. This group of objectives should parallel the main project objectives. In short, it includes the objectives of a new decision, which was not originally a part of the main project plan but which must be made for seizing some opportunities.

\section{Risk Response}

Risk response is the strategy whereby decision-makers plan how to deal with each risk they can foresee. The four kinds of response to risk are: avoid, mitigate, transfer, and accept.

\section{Pure Threats}

The term 'pure threats' of an RO stands for the disadvantages of the RO, which could cause possible deviations from the objectives associated with each alternative way of accepting the RO.

\section{Pure Opportunities}

'Pure opportunities' of an RO are the benefits that might be gained by accepting the risk of the RO, e.g. hiring a new contractor, the main goal in this method is taking advantage of RO by achieving these opportunities.

\section{Alternative}

The alternatives are the different actions that can be taken in order to accept the risk. For each alternative, the weights of an RO are calculated by means of the ANP.

\section{Stress}

We use the term 'Stress' in a novel way in this study. The major difference between this term and the usual similar terms, like risk, threat and hazard, is that Stress quantitatively includes likely threats, costs, opportunities and benefits of an event, which is going to be implemented in the new method based on risk acceptance. Thus, Stress as a novel index to show the relative importance of opportunities and benefits of an alternative to the threats and costs of it to be able to accept an RO. Mathematically, Stress is the ratio of the sum of the weights of all threats and costs to the sum of the weights of the opportunities and benefits of an alternative. These weights are calculated by ANP in the step 5 of the process (Figure 1). The Stress value changes if any changes affect the weights of the threats, costs, opportunities or benefits: their weights indeed depend on the elements of each cluster during the project life-cycle. This makes the index dynamic as it is a parameter dependent on variables, it is different from the traditional static concept of risk. The Stress value will also change if the amount of resources required for the alternatives varies due to changes in the variables.

\section{Resources}

Any project will have an initial specific amount of resources to get work done successfully including people, capital, knowledge, and/or material goods. In this method, resources are the part of the resources for the whole project that can be employed to make the changes; that is, they can be allocated to the new alternatives in order to take advantage of the ROs. They may include human resources, budget shifts, assets, material resources including consumables, and time. 
Basic consumption

Each alternative way to seize ROs implies performing new actions that consume specific amount of resources. Basic consumption stands for the cheapest alternative; in other words, basic consumption is the sum of all of the resources needed to take the new actions which constitute the alternative with the lowest cost.

Strain

Strain is the ratio of the amount of resource consumption to basic consumption (see Equation 8).

\subsection{Outline of the Steps}

Risk management is a process that typically includes 4 main steps that are updated as a cycle during the project life-cycle Conroy and Soltan (1998). However, many practitioners prefer to customize the general 4-Step Risk Management Plan with further detailed steps Burnaby and Hass (2009); Mazareanu (2011); Ward and Chapman (2008).

Figure 1 is an illustration of the cutting edge logical flow of the new method within the general 4 step model of risk management. This flowchart divides the action plan of complex processes into manageable steps. The project starts with identifying the scope and project planning: the classic risk management model is shown inside the green box. RO analysis method begins after the first step of the risk management plan - risk identification. Defining risky-opportunities takes the opportunities into consideration according to the project scope and objectives. As previously discussed, uncertain events associated with threats may include some opportunities and some positive effects. Then, different alternative ways to address the threats and seize the opportunities of ROs can be devised. Other RM methods do not consider changes, and uncertain opportunity remains unavailable.

In the following the outline of the steps of the evaluation procedure proposed in this paper is presented.

1. Implementation of the RO analysis method (ROAM) at the project level starts after defining the work breakdown structure (WBS) of the project. The first step is the definition of the main project objectives and scope, followed by clarifying the project sub-objectives, requirements, and required resources. In the case-study here discussed, the main project is digitalization of the PSP service supply chain and the sub-project is the transformation of the transaction report production into an eco-friendly method.

2. Next step is to identify alternative solutions to the traditional thermal paper receipt.

3. It is crucial to choose the feasible and most effective alternatives to continue the analysis. The following criteria will be employed to select the most advantageous alternatives:

- Economic criterion,

- Importance of achievement,

- Feasibility,

- Congruence.

4. In this step the threats associated with the selected alternatives, which are defined as ROs, are identified. The output of this step is a probability-impact scheme for the threats and impacts of each RO.

5. This step includes five sub-actions to calculate the required parameters through the ANP; the results are then employed in the next step in order to calculate Stress and Strain of the Alternatives.

(a) Identify the decision criteria for ANP.

(b) Clustering.

(c) Identify relations between clusters, and between the elements of the clusters.

(d) Construct the network.

(e) Pairwise comparison and solve the ANP Saaty (2004 2005). In this paper Super Decision 3.2 was employed to calculate the overall priorities for the threat. The 


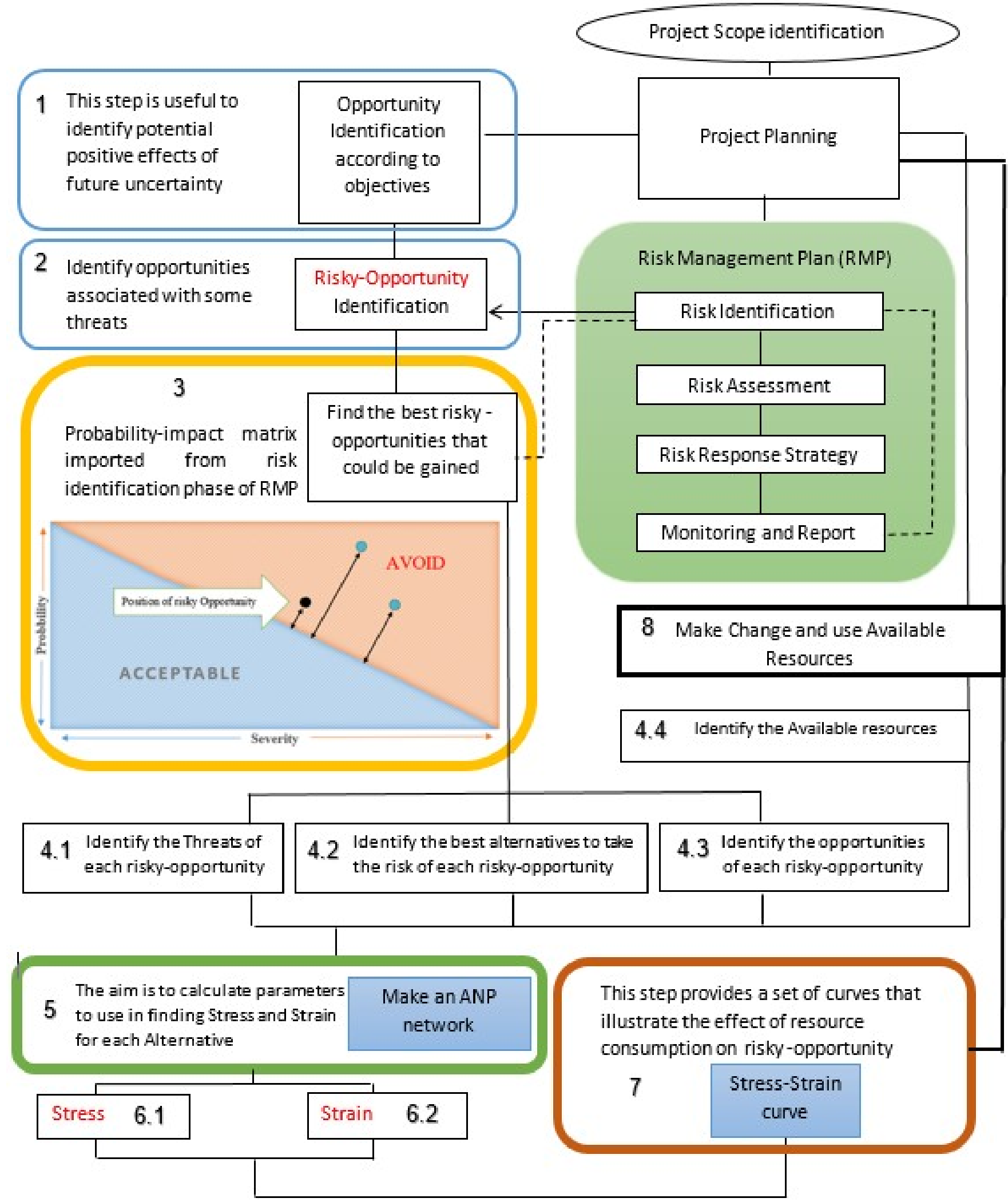

Figure 1. General process of the digitalization risk acceptance evaluation employing ROAM 
Table 1: Random Consistency Index

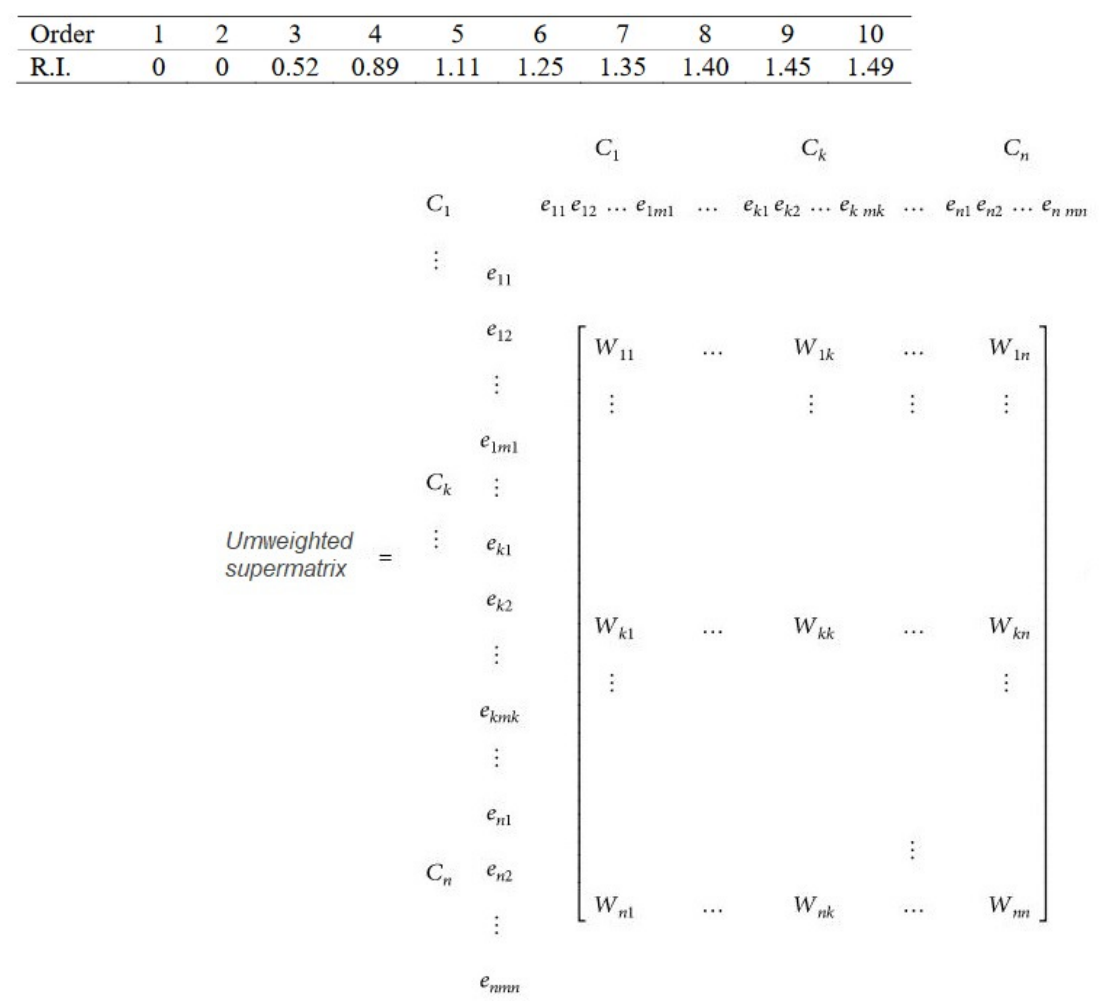

Figure 2. Unweighted Supermatrix. $\mathrm{C}$ is the cluster when $k=(1-n)$ and $W_{i j}$ is the priority vector extracted from pairwise matrix

procedure of ANP can be summarized as follows Barzilai (1997); Piantanakulchai ( 2005); Saaty and Vargas (2006):

- Construct a pairwise matrix through quantifying the preference of the decision makers using 9 scale ranking Barzilai (1997). If $\mathrm{n}$ objects should be compared, the number of comparisons is $\frac{n(n-1)}{2}$

- If $\mathrm{i}$ represent the row number and $\mathrm{j}$ represents the column number of the matrix, the lower diagonal should be equal to $\left(a_{i j}>0\right)$ :

$$
a_{j i}=\frac{1}{a_{i j}}
$$

Check the consistency ratio of the matrix using the following equations:

$$
\begin{gathered}
\lambda_{\text {max }}=\Sigma(\text { EigenVector }) \cdot \Sigma\left(\text { Col }_{j} \text { of reciprocalmatrix }\right) \\
C I=\frac{\lambda_{\max }-n}{n-1}
\end{gathered}
$$

Extract RI (Random Consistency Index) from Table 1 and calculate CR.

$$
C R=\frac{C I}{R I}
$$

- Measure the consistency from Equation 4 Koczkodaj (1993); Saaty and Vargas (2006).

- Construct the Unweighted Supermatrix Figure 2 of the network and then multiply the weights. 
- $\quad$ Raising the Weighted Supermatrix to the limiting power the global priority vectors are obtained.

$$
\lim _{k \rightarrow \infty} w^{k}
$$

In case of cyclicity effect, the Equation 6 is used

$$
\lim _{k \rightarrow \infty}\left(\frac{1}{n}\right) \sum_{i=1}^{w} W_{i}^{k}
$$

6. This step includes two sub-actions.

(a) Stress is calculated as follows:

$$
\text { Stress }_{\text {alternative }}=\frac{\sum \mathrm{TW} \cdot \mathrm{CW}}{\sum \mathrm{OW} \cdot \mathrm{AW}}
$$

where:

OW, the benefit subnetwork will calculate the weight of all of the pure opportunities for each alternative. To calculate the denominator of the stress of each alternative $\left(\mathrm{A}_{\mathrm{i}}\right)$, the pure opportunities associated with that alternative will sum up and multiply to the alternative weight.

$\mathrm{AW}$, the opportunity subnetwork will calculate the weight of alternative-i $\left(\mathrm{A}_{\mathrm{i}}\right)$ related to $\mathrm{RO}_{\mathrm{j}}$ according to the objectives.

TW, the risk subnetwork will calculate the weight of all of the pure threats for each alternative. To calculate the numerator of stress for each alternative $\left(\mathrm{A}_{\mathrm{i}}\right)$, the pure threats associated with that alternative will sum up and multiply to the cost weight. $\mathrm{CW}$, the cost subnetwork will calculate the weight of alternative-i $\left(\mathrm{A}_{\mathrm{i}}\right)$ related to $\mathrm{RO}_{\mathrm{j}}$ according to resource consumption.

(b) Strain is calculated as follows:

$$
\text { Strain }_{\text {alternative }}=\frac{\sum \mathrm{ARR}}{\mathrm{BC}}
$$

where:

ARR, Available Required Resources to perform the activities of an alternative

$\mathrm{BC}$, Basic Consumption, i.e. the resources needed by the cheapest alternative

7. In the last assessment step, Stress and Strain of each alternative are used to find the position of the $A_{i}$ in the Stress-Strain coordination system. Each alternative has a specific point in the space.

8. After the assessment, a sub-project will be introduced in the form of an operation plan in order to meet the selected alternative work-package.

\section{Outline of the Steps of the ROAM in the case-study}

In this section, ROs analysis of the PSP company employing ROAM will be explained systematically. The procedure of calculations is explained in the previous section.

\subsection{Goal of the project}

The main goal of this project is to analyze the ROs related to the socio-economic and socio-ecologic transition of a PSP company towards a green supply chain. A recent study on the PSP supply chain Aghazadeh Ardebili et al. (2020) showed that the elimination of thermal paper from the supply chain ancillary service could bring about environmental, social and economic opportunities. Specifically, the following opportunities can be mentioned: eliminating the production of toxic waste during the service supply chain, reducing the traffic caused by maintenance shuttles of the POS devices, reducing the burden of maintenance activities through digitization of the system Plesner et al. (2018); Plesner and Raviola (2016), and finally eliminating the delivery of the thermal paper to the end-users of PSP service to avoid its dangerous consequences on social health. 


\subsection{Identification of the alternatives}

In the previous studies Aghazadeh Ardebili et al. (2019 2020), two kinds of alternatives were identified in this supply chain. Using e-Receipt to eliminate thermal paper receipt production, and using a combination of e-Receipt and paper to reduce thermal paper production. Both alternatives are associated with some threats, therefore they can be considered as key ROs in this analysis.

\subsection{Feasible alternatives}

The above cited studies showed that three of the ROs are not feasible because of the cost, or high impact and probability of threat occurrence. Table 2 displays the probability and impact of the threats for each alternative. Alternatives 5,8,9 were already removed from the analysis; for the next steps of the analysis six alternatives will be considered:

RO1 includes the e-Receipt methods

A1. SMS

A2. Email

A3. Application notification

$\mathrm{RO} 2$ includes the combination of e-Receipt and paper in case of transaction failure

A1. SMS or Print

A2. Email or Print

A3. Application notification or Print.

\subsection{Probability-Impact}

The assessment of Probability-Impact of the issues related to the alternatives is necessary to support pairwise comparison. In Table 2 all of the issues, including the Threats (T), Opportunities $(\mathrm{Op})$, Benefits $(\mathrm{Be})$, Costs $(\mathrm{Co})$ of the ROs, and their alternatives are listed. Regarding the identified costs, HRM, assets of the company (servers), and budget in cash are the resources that this company needs to implement these alternatives. As can be seen in Table 2, there is no opportunity or benefit that is not likely or has a negligible impact on improving the service if the sustainability pillars are considered. In addition, there is no threat or cost that is highly likely and has an extreme impact on making problem in the service. Therefore, we will not eliminate any alternative.

\subsection{Parameters Calculation}

This step includes different sub-steps to construct the network and solve them by the ANP.

\subsubsection{Decision criteria}

The decision criteria in the current analysis are chosen according to all three sustainability pillars, because the main goal of accepting RO aims at transforming the supply chain ecologically, economically, and socially towards a green supply chain. However, the key to this transition is the digitalization process Jedynak et al. (2021); Liu et al. (2021); therefore, the technological aspect is also included among the criteria in this analysis.

\subsubsection{Clustering}

The elements for each cluster are listed in separated table similar to the example of the threats in Table 2 (the tables for opportunity, cost, and benefit are available in the Appendix - see A). The criteria column in the table illustrate how each element is related to decision criteria.

\subsubsection{Relations}

The relation between the T, Co, Be, Op, and the alternatives are shown in Figure 3. The colored box emphasizes a relation between the issue in the Column and the ROiAj in the row. For instance, $\mathrm{T} 1$ is a threat that has impact on $\mathrm{RO} 2 \mathrm{~A} 2$, and $\mathrm{RO} 2 \mathrm{~A} 3$. This relation will be used in constructing the network and pairwise analysis of the ANP. Moreover, Alternative no. 5, 8, and 9 were already eliminated in the Step 3 of the current procedure. 
Table 2: "Pure Threat" cluster elements

\begin{tabular}{|c|c|c|c|c|c|c|}
\hline \multirow{2}{*}{ No. } & \multicolumn{2}{|c|}{ Threat Description } & \multicolumn{4}{|c|}{ Criteria } \\
\hline & issue & Threat & Soc. & Econ. & Env. & Tec. \\
\hline$T 1$ & Security & Information Accuracy & * & & & * \\
\hline$T 2$ & & Cybersecurity & * & & & * \\
\hline$T 3$ & Service adoption & Purchaser & * & & & \\
\hline$T 4$ & & Vendor & * & & & \\
\hline$T 5$ & Availability & Purchaser & & & & * \\
\hline$T 6$ & & Vendor & & * & & * \\
\hline$T 7$ & Environment & Unnecessary shuttles & * & & $*$ & \\
\hline$T 8$ & & Thermal paper usage & * & * & $*$ & $*$ \\
\hline$T 9$ & Service providing & Data transfer speed & & & & * \\
\hline$T 10$ & issues & Troubleshooting speed & & & & $*$ \\
\hline$T 11$ & Infrastructure & $\begin{array}{l}\text { Internal Network (national } \\
\text { intemet) }\end{array}$ & * & $*$ & & * \\
\hline$T 12$ & & Intemet connection & & * & & * \\
\hline$T 13$ & & $\begin{array}{c}\text { Telecommunication network } \\
\text { issues }\end{array}$ & & & & $*$ \\
\hline$T 14$ & & Network data issues & & & & $*$ \\
\hline T15 & & Mobil intemet issues & * & & & * \\
\hline
\end{tabular}

\subsubsection{Network construction}

In Figure 3, the general Risk network, which refers to pure threats cluster, and the constructed network for ranking the threats regarding the socio-economic transition problem in SuperDecision V3.2 are shown.

\subsubsection{Pairwise comparison}

The pairwise comparisons were made through data collected in semi-structured interviews, and the geometric mean of all values were used for building the pairwise matrix. The tables in Figure 3 show the unweighted supermatrix and the limit supermatrix of the risk network to define the priorities of the pure threats. The final normalized priorities of all parameters are shown in Figure 4.

\subsection{Stress and Strain calculation}

Stress and Strain were calculated for each alternative employing the parameters produced in the previous step, and they are reported in the next two subsections.

\subsubsection{Stress}

Stress is calculated through Equation 7 in Section 2 and the information extracted from the relation table (see Figure $3-$ a). The results are listed in Table 4. In the following the implementation of the Equation 7 is shown for Stress RO1A1. From the table of Figure 3 (a), the threats which are related to alternative RO1A1 are T11, T13, and T14. The results of ANP in Figure 4 show that the weights of these threats are all equal to 0.060691. In the same way and using the results of the ANP analysis in Figure 4, the related resources are Co1 $=0.276495$, $\mathrm{Co} 2=0.432281$, and Co3 $=0.291225$; Opportunities are Op6 $=0.028055$ and Op8 $=0.045125$, and benefits are $\mathrm{Be} 1=0.052110, \mathrm{Be} 2=0.506275, \mathrm{Be} 3=0.72325$, Be $4=0.369290$. All of the other Stress values in Table 4 are calculated in the same way.

\section{Stress $\mathrm{RO}_{1} \mathrm{~A}_{1}=\frac{(0.060691 * 3) *(0.276495+0.432281+0.291225)}{(0.028055+0.045125) *(0.052110+0.506275+0.72325+0.369290)}$}

Stress $\mathrm{RO}_{1} \mathrm{~A}_{1}=2.488018$

While Stress is a dimensionless value, Strain is measured in currency in this study. The amount of Strain for different alternatives could be very different. Therefore, to express all the values of numeric columns in a common scale, we normalize them. These values will be re-scaled to make all the elements lie between 0 and 1 (Table 4). Linear normalization is used to normalize the final Stress and Strain values employing $n_{i j}=r_{i j} / \sum r_{i j}$ Vafaei et al. (2016). 


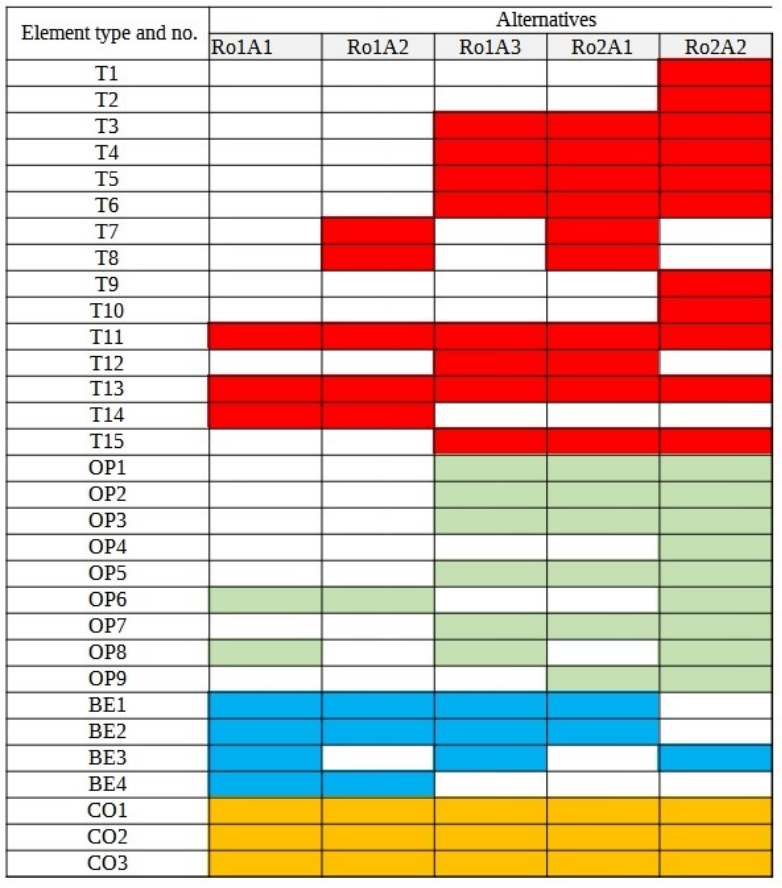

(a) The relation between $\mathrm{T}, \mathrm{Co}, \mathrm{Be}, \mathrm{Op}$ and alternatives.

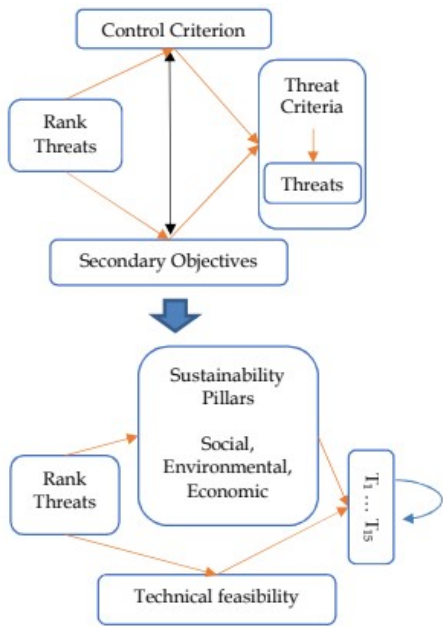

(b) Risk Network map.

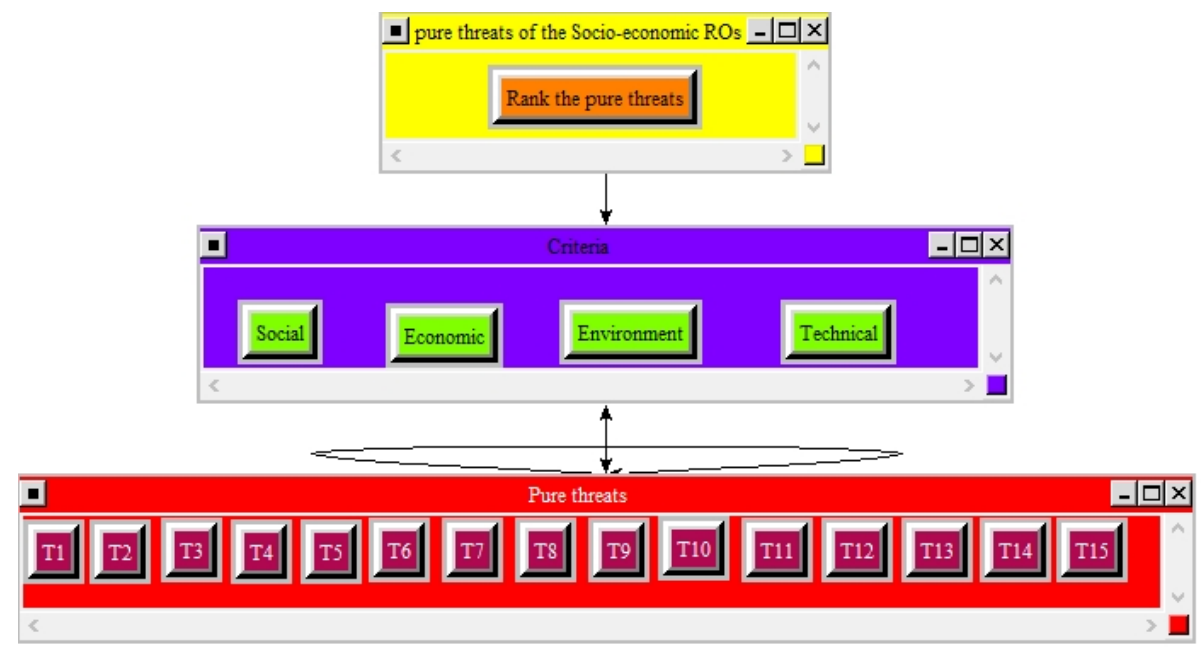

(c) The Risk network (Elaborated by Super decision Version 3.2.

Figure 3. Risk Network of the current study

Table 3: Threats unweighted supermatrix (exported from SuperDecision V3.2)

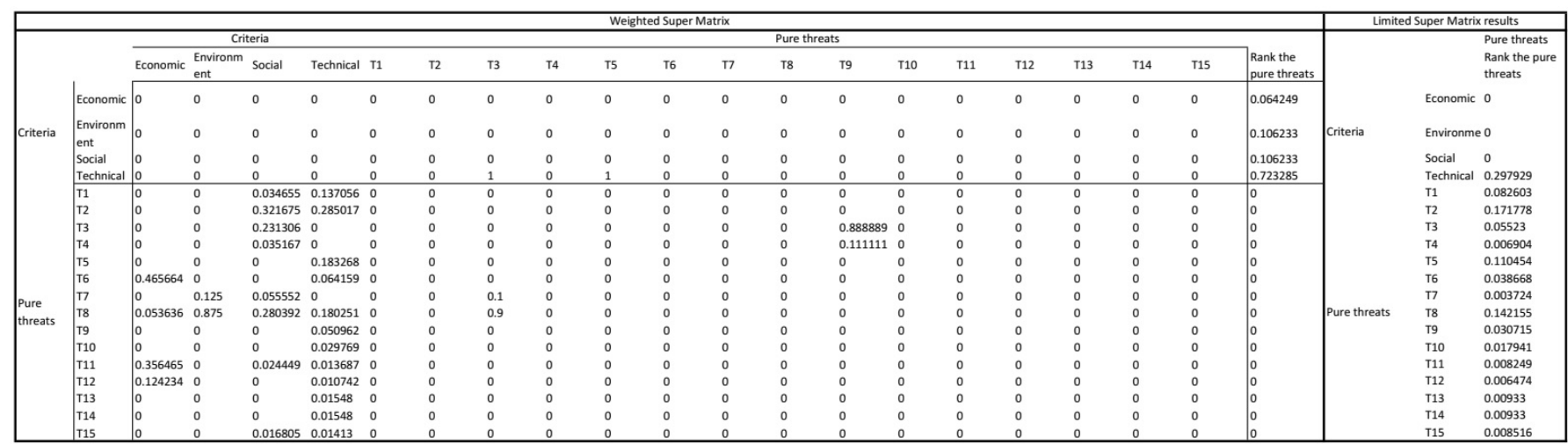




\begin{tabular}{|c|c|c|c|c|}
\hline Name & Graphic & Ideals & Normals & 5 Raw \\
\hline Be1 & & \begin{tabular}{|l|l|l} 
\\
\end{tabular} & 0.052110 & 0.022990 \\
\hline $\mathrm{Be} 2$ & & 1.000000 & 0.506275 & 0.223356 \\
\hline $\mathrm{Be} 3$ & & 0.142857 & \begin{tabular}{|l|l} 
& 0.072325 \\
\end{tabular} & 0.031908 \\
\hline Be4 & & 0.729426 & 0.369290 & 0.162922 \\
\hline
\end{tabular}

(a) Priorities for the Benefits.

\begin{tabular}{|c|c|c|c|c|}
\hline Name & Graphic & Ideals & Normals & Raw \\
\hline $\mathrm{T1}$ & & 0.526833 & 0.060691 & 0.047725 \\
\hline $\mathrm{T} 2$ & & 0.526833 & 0.060691 & 0.047725 \\
\hline T3 & & 0.706088 & 0.081342 & 0.063963 \\
\hline T4 & & 0.706088 & 0.081342 & 0.063963 \\
\hline T5 & & 0.526833 & 0.060691 & 0.047725 \\
\hline T6 & & 0.526833 & 0.060691 & 0.047725 \\
\hline T7 & & 0.473167 & 0.054509 & 0.042863 \\
\hline T8 & & 1.000000 & 0.115201 & 0.090588 \\
\hline T9 & & 0.526833 & 0.060691 & 0.047725 \\
\hline $\mathrm{T} 10$ & & 0.526833 & 0.060691 & 0.047725 \\
\hline T11 & & 0.526833 & 0.060691 & 0.047725 \\
\hline $\mathrm{T} 12$ & & 0.526833 & 0.060691 & 0.047725 \\
\hline $\mathrm{T} 13$ & & 0.526833 & 0.060691 & 0.047725 \\
\hline T14 & & 0.526833 & 0.060691 & 0.047725 \\
\hline T15 & & 0.526833 & 0.060691 & 0.047725 \\
\hline
\end{tabular}

(b) Priorities for the Threats.

\begin{tabular}{|c|c|c|c|c|}
\hline Name & Graphic & Ideals & Normals & Raw \\
\hline Op1 & $\square$ & 0.077074 & 0.042966 & 0.021483 \\
\hline Op2 & & 0.233776 & 0.130323 & 0.065162 \\
\hline Op 3 & & 0.261652 & 0.145863 & 0.072932 \\
\hline Op4 & & 1.000000 & 0.557471 & 0.278736 \\
\hline Op5 & $\square$ & 0.050326 & 0.028055 & 0.014028 \\
\hline Op6 & ] & 0.050326 & 0.028055 & 0.014028 \\
\hline Op7 & & 0.000000 & 0.000000 & 0.000000 \\
\hline Op8 & 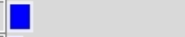 & 0.080946 & 0.045125 & 0.022563 \\
\hline Op9 & ! & 0.039715 & 0.022140 & 0.011070 \\
\hline
\end{tabular}

(d) Priorities for the Opportunities (c) Priorities for the Resources deals Normals Raw

\begin{tabular}{|c|c|c|c|c|}
\hline Name & Graphic & Ideals & Normals & Raw \\
\hline Assets (Servers) & & 0.639619 & 0.276495 & 0.12198 \\
\hline Budget & & 1.000000 & \begin{tabular}{|l|l|}
0.432281 \\
\end{tabular} & 0.19071 \\
\hline Human resource & & 0.673693 & 0.291225 & 0.12848 \\
\hline
\end{tabular}

Figure 4. Overall priorities produced by SuperDecision Version 3.2)

Table 4: Stress table

\begin{tabular}{|c|c|c|c|c|c|c|}
\hline Alternative & $R O 1 A 1$ & $R O 1 A 2$ & $R O 1 A 3$ & $R O 2 A 1$ & $R O 2 A 2$ & $R O 2 A 3$ \\
\hline Stress & 2.488018 & 13.51665 & 2.129059 & 3.377369 & 9.801651 & 12.72224 \\
\hline $\begin{array}{c}\text { Normalized } \\
\text { Stress }\end{array}$ & 0.0565 & 0.3070 & 0.0483 & 0.0767 & 0.2226 & 0.2889 \\
\hline
\end{tabular}

\subsubsection{Strain}

The Strain calculation table is shown in Table 5. The costs are in Iranian Rial, the salary is the average salary for an expert with 10 years of experience in the Persian year of 1398 . The price of the thermal paper is referred to 7 January 2020; however, this price is subject to high fluctuation due to the fact that it is not produced internally but imported. National Internet cost is negligible in Iran because the National Internet is very cheap in order to encourage companies and users to use National Internet instead of a global system of interconnected computer networks (Internet). The costs in the following table include the cost of establishing a new service and the first month of implementing the service. To calculate the Strain of each alternative Equation 8 from Section 2 is employed.

\section{Results and Discussion}

In Figure 5, considering that the vertical axis in the coordinate plane is Strain, the significant high Stress and Strain of the RO2A3 shows that the benefits and opportunities of this alternative do not outweigh its threats and costs; it is very expensive alternative in comparison with the other alternatives. The other alternatives have better performances, so this alternative can be removed from further analysis. Blue and red points show that the transitions from RO2A2 and RO1A2 
Table 5: Strain calculation table

\begin{tabular}{|c|c|c|c|c|}
\hline & COST CALCULATION & Cost & STRAIN & NORM. \\
\hline 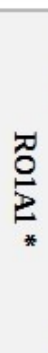 & $\begin{array}{l}\text { [ } 80 \text { (cost of SMS in Iran in "Iranian Rial" )* } 4 \\
\text { (length of the text message regarding the } \\
\text { characters that are in the SMS is equal to } 4 \\
\text { SMS in Persian )* } 2 \text { (for each transaction two } \\
\text { SMS is required including customer and } \\
\text { vendor) * } 31973 \text { (Average tax in a specific } \\
\text { macro zone regarding the results of Chapter } 4 \text { ) } \\
\text { ] + [ } 2 \text { (switch developer, POS developer) * } \\
\text { DS }{ }^{1} * 160 \mathrm{~h} \text { (stablish new service)+ DS * } 20 \mathrm{~h} \\
\text { (outsourcing coordination and maintenance )] }\end{array}$ & 88462720 & 1.382 & 0.1732 \\
\hline$\stackrel{0}{0}$ & $\begin{array}{l}\text { 2(switch developer, POS developer)*DS* } \\
\text { 160h (implementation) }\end{array}$ & 64000000 & 1.000 & 0.1253 \\
\hline 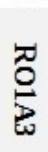 & $\begin{array}{l}2 \text { (switch developer, POS developer) * DS * } \\
160 \text { h (stablish new service) + DS * 196h } \\
\text { (application support service, CRM and cyber } \\
\text { security measures) }\end{array}$ & 103200000 & 1.613 & 0.2021 \\
\hline 党 & $\begin{array}{l}\text { [( } 80 * 4 * 2 * 30457 \text { (successful tax in macro } \\
\text { zone))+ Paper receipt price ( } 26000 \text { (price of } \\
\text { each role of the thermal paper) IR / ( } 20 \mathrm{~m} \\
\text { (length of the role of the thermal } \\
\text { paper) } / 4.5 \mathrm{~cm}(\text { minimum of size)) }=58.5 \mathrm{IR}) * \\
1472 \text { (unsuccessful tax in macro zone)]+ [ } 2 \\
\text { (switch developer, POS developer) * DS } \\
\text { (Developer Salary per hour (DS) = average } \\
40000000 \mathrm{IR} / 196 \mathrm{~h}=200000)^{*} 160 \mathrm{~h} \\
\text { (stablish new service)+ DS * } 20 \mathrm{~h} \text { (maintenance } \\
\text { per month)] }\end{array}$ & 87578592 & 1.368 & 0.1715 \\
\hline 总 & $\begin{array}{l}\text { Paper receipt price * } 1472 \text { (unsuccessful tax in } \\
\text { macro zone) }+2 \text { (switch developer, POS } \\
\text { developer)*DS* } 160 \text { h(stablish new service)+ } \\
\text { DS*20h (maintenance per month) }\end{array}$ & 64086112 & 1.001 & 0.1255 \\
\hline 疍 & $\begin{array}{l}\text { Paper receipt price *1472 (unsuccessful tax in } \\
\text { macro zone)+ DS*20h(maintenance per } \\
\text { month)* DS * 160h (stablish new service) + } 2 \\
\text { * DS * 196h (application support service, } \\
\text { CRM and cyber security measures) }\end{array}$ & 103286112 & 1.614 & 0.2023 \\
\hline
\end{tabular}

Developer Salary per hour $(D S)=$ average $40000000 I R / 196 \mathrm{~h}=200000$

Cost $_{\text {ROIAI }}=(80 * 4 * 2 * 31973)+(2 * 160 * 200000)+(20 * 200000)=88462720$

Strain $_{\text {ROIAl }}=$ Cost $_{\text {ROIA1 }} /$ Cost $_{\text {ROIA2 }}=1.38223$

Normalized Strain $_{\text {ROIAl }}=$ Strain $_{\text {ROIAI }} / \sum_{i=1}^{2} \sum_{j=1}^{3}$ StrainROiAj 


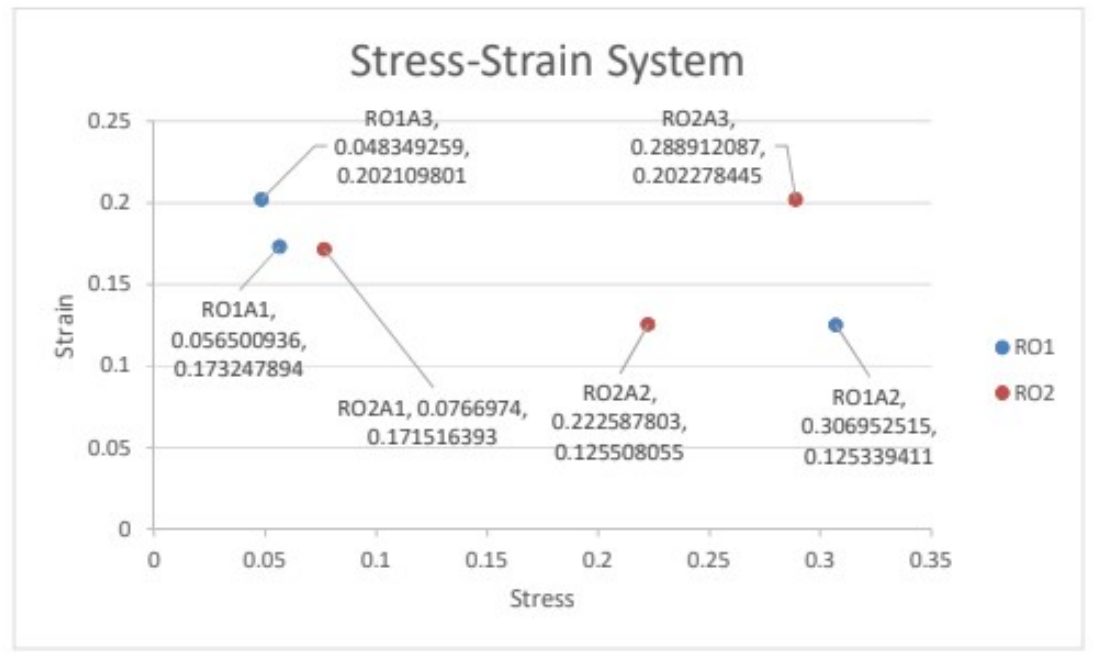

Figure 5. Strain Stress illustration

towards the other alternatives increase the Strain but decrease the Stress. RO2A2 and RO1A3 are cheaper alternatives but they have a high stress. Therefore, RO2A1, RO1A1 and RO1A3 are better to accept; because in comparison with the stress of RO2A2 and RO1A3, imposing some changes and considering the cost of the changes will cause increase of strain, but the stress decreases sharply and it provides safe condition to accept the ROs.

Since RO2A1 has higher Stress, we focus on the transition from this alternative towards RO1A1 and RO1A3. The Strain of RO1A3 is higher than RO2A1. It points to the fact that with a small amount of higher resource consumption, the Stress of the target alternative will decrease. Nevertheless, the strain of RO2A1 is almost equal to the Strain of RO1A1 and this proves that the cost for establishing the ancillary service of e-Receipt by 'SMS' is almost equal to 'SMS and paper receipt'. The weight of the threats and costs of providing e-Receipt by SMS in case of successful transaction and paper receipt in case of transaction failure is higher than its opportunities and benefits. This Strain and Stress values confirm that providing e-Receipt by SMS in all scenarios is the best alternative. RO1A1 has less Strain than RO1A3; however, the Stress is not significantly higher; this supports the choice of RO1A1 as the best alternative. In this particular case, RO1A2 (the cheapest) and RO2A2 have the lowest resource consumption rate; and RO1A3 has the lowest Stress. However, RO1A1 might be selected regarding the transitions that discussed.

\section{Conclusions}

Practical sustainable development is a multidisciplinary innovative/collaborative approach that ensures a reliable future for next generations. Digitalization is an eminent example of innovative trends that is taking place in CPSS. Nevertheless, with all opportunities behind socioecological, socio-economic, and socio-technical transition, the transition is not free of risk. The complexity of the CPSS and the significance of continuity of functioning of an infrastructure, boost the risks of sustainable transformation of a PSP. Therefore, this transition is a RO: the pure threats it will pose should be considered alongside the unique opportunities. The ROAM method showed a high capacity in dealing with risk-based decisions that should be made in order to establish hazard free service.

The results of the case study support the conclusion that RO1A1 (SMS) is the best alternative to accept because the Stress decreases significantly with small resource consumption, meaning that the risk-taking capability of the company for establishing the ancillary service of providing e-Receipt is higher than that provided by the other alternatives. In a previous work, Aghazadeh Ardebili et al. (2020) employed an MCDM TOPSIS model to assess the same alternatives regardless of the uncertainty and possibility of taking the risks. That model showed that RO1A3 (Application Notification) was the preferable option. This significant contradiction reveals the importance of taking the positive and negative effects in account when the alternatives 
of analysis are risky-opportunities. In fact, when we consider the risk-taking capability of a company confronting a Risky-Opportunity, the result of the evaluation in conditions of certainty could differ from that obtained when uncertainty is taken into consideration.

Author Contributions: Ali Aghazadeh Ardebili and Elio Padoano have participated in (a) conception and design, analysis and interpretation of the data; (b) drafting the article or revising it critically for important intellectual content; and all authors participated in (c) proof reading and refining the final version.

Funding: The authors received no funding for the research, authorship, and/or publication of this article.

Acknowledgments: Doctor Rozann W. Saaty's suggestions were fundamental in defining the path of my research. For this, I am extremely grateful.

Also I would like to acknowledge Dr. Mohammad Reza Mazandarani, Najmeh Rahmani, Ph.D. candidates Babak Firoozi, and Luca Toneatti for proofreading the manuscript of the current document.

Conflicts of Interest: The Authors have no conflicts of interest to disclose.

The authors have no affiliation with any organization with a direct or indirect financial interest in the subject matter discussed in the manuscript.

\section{Appendix A Future issues}

\section{(Risks, Opportunities, Benefits, Costs are categorized and listed)}

In the Tables whose links are reported below, the probability is a percentage between 0 and 100 , in which 0 means the issue will not happen, and 100 means the issue will certainly happen. The impact is an integer between 0 and 10, in which 0 means the issue has no impact on the project and its goals, and 10 means the issue has an extremely strong impact on the project and its goals.

Information Security is an issue related with security. It has a low probability of occurrence and a very strong impact when one of the alternatives of RO1 is implemented.

Future Issues Table 1

https://drive.google.com/file/d/1QQV1uFY433Tu-CmtE0jf6rbZOfLbU1BK/view?usp=sharing Future Issues Table 2

https://drive.google.com/file/d/19qjEarFUT8jFZGsd6QId0KGCfu8-Qs08/view?usp=sharing

\section{Appendix B $[\mathrm{C}, \mathrm{O}, \mathrm{B}]$ clusters}

Clusters Table 1, 2, 3

https://drive.google.com/file/d/1fH8ZBvaqdkUWoCqj1Q-28oYOMnXGFeiU/view?usp=sharing

Aghazadeh Ardebili, A. 2020, 6. A method to support risk management and resource allocation in projects based on risk acceptance strategy. PhD dissertation, University of Trieste. Department of Engineering and Architecture - Dia.

Aghazadeh Ardebili, A., E. Padoano, and R. Najmeh. 2019. Providing green services-the case study of thermal paper waste and unnecessary transportations in the payment service. In F.-J. V. Elio Padoano (Ed.), 9 International Conference, PEM 2019, pp. 103-114.

Aghazadeh Ardebili, A., E. Padoano, and N. Rahmani. 2020. Waste reduction for green service supply chain - the case study of a payment service provider in iran. Sustainability 12(5), 1833.

Akilarasan, M., S. Kogularasu, S. Chen, T. Chen, and B. Lou. 2018. A novel approach to iron oxide separation from e-waste and bisphenol a detection in thermal paper receipts using recovered nanocomposites. RSC Advances 8(70), 39870-39878.

Alban, L., B. Häsler, G. van Schaik, and S. Ruegg. 2020. Risk-based surveillance for meat-borne parasites. Experimental Parasitology 208, 107808.

Andersen, K. V., R. Beck, R. T. Wigand, N. Bjørn-Andersen, and E. Brousseau. 2004. European e-commerce policies in the pioneering days, the gold rush and the post-hype era. Information Polity 9(3-4), 217-232.

Arva, M., N. Bizon, and O. Novac. 2020. Electronic receipts using near-field communication protocol as a solution for thermal paper receipts. In Proceedings of the 12th International Conference on Electronics, Computers and Artificial Intelligence, ECAI 2020. 
Asenova, D., W. Stein, and A. Marshall. 2011, 8. An innovative approach to risk and quality assessment in the regulation of care services in scotland. Journal of Risk Research 14(7), 859-879. doi: 10.1080/13669877.2011.571780.

Azapagic, A. 2003, 9. Systems approach to corporate sustainability. Process Safety and Environmental Protection 81(5), 303-316. doi:10.1205/095758203770224342.

Azapagic, A. 2010. Chapter 7. life cycle assessment as a tool for sustainable management of ecosystem services. In Issues in Environmental Science and Technology, pp. 140-168. Royal Society of Chemistry. doi:10.1039/9781849731058-00140.

Barzilai, J. 1997. Deriving weights from pairwise comparison matrices. Journal of the Operational Research Society 48(12), 1226-1232.

Bechtold, U., D. Fuchs, and N. Gudowsky. 2017, May. Imagining socio-technical futures - challenges and opportunities for technology assessment. Journal of Responsible Innovation 4(2), 85-99. doi: 10.1080/23299460.2017.1364617.

Blos, M. F., H. M. Wee, and J. Yang. 2010. Analysing the external supply chain risk driver competitiveness: a risk mitigation framework and business continuity plan. Journal of Business Continuity \& Emergency Planning 4(4), 368-374.

Braun, J. M., K. Yolton, K. N. Dietrich, R. Hornung, X. Ye, A. M. Calafat, and B. P. Lanphear. 2009. Prenatal bisphenol a exposure and early childhood behavior. Environmental Health Perspectives 117(12), 1945-1952.

Burnaby, P. and S. Hass. 2009. Ten steps to enterprise-wide risk management. Corporate Governance 9(5), 539-550.

Buyya, R., C. Shin Yeo, and S. Venugopal. 2008. Market-oriented cloud computing: Vision, hype, and reality for delivering it services as computing utilities. In 10th IEEE international conference on high performance computing and communications, pp. 5-13. IEEE.

Buyya, R., C. S. Yeo, S. Venugopal, J. Broberg, and I. Brandic. 2009. Cloud computing and emerging it platforms: Vision, hype, and reality for delivering computing as the 5 th utility. Future Generation Computer Systems 25(6), 599-616.

Chen, W. and M. Dong. 2018. Optimal resource allocation across related channels. Operations Research Letters 46(4), 397-401. doi:10.1016/j.orl.2018.04.004.

Choi, J. K., J. S. Park, J. H. Lee, and K. S. Ryu. 2006. Key factors for e-commerce business success. In Proceedings of the 8th International Conference Advanced Communication Technology, ICACT 2006, Volume 3, pp. 1664-1672.

Conroy, G. and H. Soltan. 1998. ConSERV, a project specific risk management concept. International Journal of Project Management 16(6), 353-366. doi:10.1016/S0263-7863(98)00012-X.

Domar, E. D. and R. A. Musgrave. 1944. Proportional income taxation and risk-taking. The Quarterly Journal of Economics 58(3), 388-422. doi:10.2307/1882847.

Dos Santos Paulino, V. 2009, May. Organizational change in risky environments: space activities. Journal of Organizational Change Management 22(3), 257-274. doi:10.1108/09534810910951050.

Eduardsen, J. 2018. Internationalisation through digitalisation: The impact of e-commerce usage on internationalisation in small-and medium-sized firms, Volume 13 of Progress in International Business Research. Emerald.

Ehrlich, S., A. M. Calafat, O. Humblet, T. Smith, and R. Hauser. 2014. Handling of thermal receipts as a source of exposure to bisphenol a. Jama 311(8), 859-860.

El Bassiouny, N., M. Darrag, and N Zahran. 2018, June. Corporate social responsibility (CSR) communication patterns in an emerging market. Journal of Organizational Change Management 31(4), 795-809. doi:10.1108/jocm-03-2017-0087.

Engelhard, K. and Ch. Böhm. 2013. Security of supply chains from a service provider's perspective. In Supply Chain Safety Management, pp. 167-178. Springer Berlin Heidelberg. doi:10.1007/978-3-64232021-7_10.

Glerup, C. and M. Horst. 2014, January. Mapping 'social responsibility' in science. Journal of Responsible Innovation 1(1), 31-50. doi:10.1080/23299460.2014.882077.

Goel, H. and T. Venkat Narayana Rao. 2019. Data visualization in e-commerce an indispensable implementation in real world business scenario. International Journal of Scientific and Technology Research 8(10), 2447-2450.

Grant, K., J. White, J. Martin, and T. Haines. 2019. The costs of risk and fear: a qualitative study of risk conceptualisations in allied health resource allocation decision-making. Health, Risk \& Society 21(7), 373-389. Publisher: Taylor \& Francis, doi:10.1080/13698575.2019.1667962. 
Gravesteijn, M. and C. P. M. Wilderom. 2018. Participative change toward digitalized, customer-oriented continuous improvements within a municipality. Journal of Organizational Change Management 31(3), 728-748. doi:10.1108/jocm-05-2016-0100.

Hetrick, J. C. 1969. A formal model for long range planning 2 assessment of opportunity and risk. Long Range Planning 1(4), 54-65.

Hietala, M. and R. Geysmans. 2020. Social sciences and radioactive waste management: acceptance, acceptability, and a persisting socio-technical divide. Journal of Risk Research, 1-16. doi: 10.1080/13669877.2020.1864010.

Hillson, D. 2003. Effective Opportunity Management for Projects: Exploiting Positive Risk. CRC Press.

Holton, J. A. 2020. Social movements thinking for managing change in large-scale systems. Journal of Organizational Change Management 33(5), 697-714. doi:10.1108/jocm-05-2019-0152.

Ivascu, L. and L.-I. Cioca. 2014. Opportunity risk: integrated approach to risk management for creating enterprise opportunities. Advances in Education Research 49(1), 77-80.

Jamali, G., E. K. Asl, S. H. Zolfani, and J. Šaparauskas. 2017. Analysing larg supply chain management competitive strategies in iranian cement industries. E a M: Ekonomie a Management 20(3), 70-83.

Jean-Jules, J. and R. Vicente. 2020. Rethinking the implementation of enterprise risk management (ERM) as a socio-technical challenge. Journal of Risk Research 24(2), 247-266. doi: 10.1080/13669877.2020.1750462.

Jedynak, M., W. Czakon, A. Kuźniarska, and K. Mania. 2021. Digital transformation of organizations: what do we know and where to go next? Journal of Organizational Change Management 34(3), 629-652. doi: 10.1108/jocm-10-2020-0336.

Ji, G. and C. Zhu. 2008. Study on supply chain disruption risk management strategies and model. In 2008 International Conference on Service Systems and Service Management, pp. 1-6. doi:10.1109/ICSSSM.2008.4598472.

Johannes, G. van der, A. and Dick T. H. M. Sijm. 2021, March. Risk governance in the transition towards sustainability, the case of bio-based plastic food packaging materials. Journal of Risk Research, 1-13. doi:10.1080/13669877.2021.1894473.

Karimi, I. A. 2009. Chemical logistics - going beyond intra-plant excellence. Computer Aided Chemical Engineering 27-C(C), 29-34.

Kirudja, C. M. 1978. Planning and resource allocation with goal programming in a structured management decision environment: the case of an Ontario general hospital. Ph. D. thesis, Western University.

Koczkodaj, W. W. 1993. A new definition of consistency of pairwise comparisons. Mathematical and Computer Modelling 18(7), 79-84.

Krueger Jr, N. and P. R. Dickson. 1994. How believing in ourselves increases risk taking: Perceived self-efficacy and opportunity recognition. Decision Sciences 25(3), 385-400.

Lefcourt, H. M. 1965. Risk taking in negro and white adults. Journal of Personality and Social Psychology 2(5), 765-770. Place: US Publisher: American Psychological Association, doi:10.1037/h0022716.

Lenjani, A., I. Bilionis, S. J. Dyke, C. M. Yeum, and R. Monteiro. 2020. A resilience-based method for prioritizing post-event building inspections. Natural Hazards 100(2), 877-896. doi:10.1007/s11069-01903849-0.

Li, Y., T. Wang, X. Song, and G. Li. 2016. Optimal resource allocation for anti-terrorism in protecting overpass bridge based on ahp risk assessment model. KSCE Journal of Civil Engineering 20(1), 309-322.

Liu, J., Yang. W., and W. Liu. 2021. Adaptive capacity configurations for the digital transformation: a fuzzy-set analysis of chinese manufacturing firms. Journal of Organizational Change Management aheadof-print(ahead-of-print). doi:10.1108/jocm-02-2020-0043.

Ma, D. J. 2013. E-commerce model research based on cloud service. Advanced Materials Research 605-607, 2534-2537. doi:10.4028/www.scientific.net/AMR.605-607.2534.

Mazareanu, V. P. 2011. Understanding risk management in small 7 steps. Revista tinerilor economisti 16, 75-80. Publisher: Editura Universitaria Craiova.

Millet, I. and W. C. Wedley. 2002. Modelling risk and uncertainty with the analytic hierarchy process. Journal of Multi-Criteria Decision Analysis 11(2), 97-107. doi:https://doi.org/10.1002/mcda.319.

Mohammadi, M. F., A. Najafi, and F. Ahmadlo. 2015. Using the analytical network process (ANP) based on BOCR model to select the most suitable region for forestation with almond species. Nusantara Bioscience 7(2). doi:10.13057/nusbiosci/n070210.

Olsson, R. 2007. In search of opportunity management: Is the risk management process enough? International Journal of Project Management 25(8), 745-752. doi:10.1016/j.ijproman.2007.03.005.

Pallaro, E., N. Subramanian, M. D. Abdulrahman, C. Liu, and K. H. Tan. 2017, 7. Review of sustainable service-based business models in the chinese truck sector. Sustainable Production and Consumption 11, 31-45. doi:10.1016/j.spc.2016.07.003. 
622 Paterson, J., P. Berr, K. Ebi, and L. Varangu. 2014. Health care facilities resilient to climate change impacts International Journal of Environmental Research and Public Health 12, 13097-13116.

624 Peker, I., B. Baki, M. Tanyas, and I. Murat Ar. 2016. Logistics center site selection by ANP/BOCR analysis: A case study of turkey. Journal of Intelligent \& Fuzzy Systems 30(4), 2383-2396. doi: 10.3233/IFS-152007.

${ }_{627}$ Piantanakulchai, M. 2005. Analytic network process model for highway corridor planning. In Proceedings of the ISAHP, pp. 8-10.

629 Pidgeon, N. 2014. Complexity, uncertainty and future risks. Journal of Risk Research 17(10), 1269-1271. doi:10.1080/13669877.2014.940599.

631 Pidgeon, N. 2020. Engaging publics about environmental and technology risks: frames, values and deliberation. Journal of Risk Research 24(1), 28-46. doi:10.1080/13669877.2020.1749118.

633 Plesner, U., L. Justesen, and C. Glerup. 2018. The transformation of work in digitized public sector

635

636

637

638

639

640

641 organizations. Journal of Organizational Change Management 31(5), 1176-1190. doi:10.1108/jocm-062017-0257.

Plesner, U. and E. Raviola. 2016. Digital technologies and a changing profession. Journal of Organizational Change Management 29(7), 1044-1065. doi:10.1108/jocm-09-2015-0159.

Rajesh, M., A. Baisel, T. N. V. R. L. Swamy, and R. Sudhakar. 2017. e-payment technology as an interface between bank and the end user. Journal of Advanced Research in Dynamical and Control Systems 9(15), 321-327.

Rehman, S. U., J. Coughlan, and Z. Halim. 2012. Usability based reliable and cashless payment system (rcps). International Journal of Innovative Computing, Information and Control 8(4), 2747-2759.

Saaty, T. L. 2001. Fundamentals of the analytic hierarchy process. In D. L. Schmoldt, J. Kangas, G. A. Mendoza, and M. Pesonen (Eds.), The Analytic Hierarchy Process in Natural Resource and Environmental Decision Making, Managing Forest Ecosystems, pp. 15-35. Springer Netherlands. doi: 10.1007/978-94-015-9799-9\_2.

Saaty, T. L. 2004. Decision making the analytic hierarchy and network processes (ahp/anp). Journal of Systems Science and Systems Engineering 13(1), 1-35.

Saaty, T. L. 2005. Making and validating complex decisions with the ahp/anp. Journal of Systems Science and Systems Engineering 14(1), 1-36.

Saaty, T. L. 2008. Decision making with the analytic hierarchy process. International Journal of Services Sciences 1(1), 83-98. doi:10.1504/IJSSci.2008.01759.

Saaty, T. L. 2015. A marijuana legalization model using benefits, opportunities, costs and risks (BOCR) analysis. International Journal of Strategic Decision Sciences 6(2), 1-11. doi:10.4018/ijsds.2015040101.

Saaty, T. L. and K. Peniwati. 2013. Group Decision Making: Drawing Out and Reconciling Differences. RWS Publications.

Saaty, T. L. and L. G. Vargas. 2006. Decision Making with the Analytic Network Process, Volume 282. Springer.

Salama, M. A., N. El-Bendary, and A. E. Hassanien. 2011. Towards secure mobile agent based e-cash system. In R. Chbeir and B. Al Bouna (Eds.), SeceS '11: Proceedings of the First International Workshop on Security and Privacy Preserving in e-Societies, pp. 1-6.

Schweizer, P.-J. 2019. Systemic risks - concepts and challenges for risk governance. Journal of Risk Research 24(1), 78-93. doi:10.1080/13669877.2019.1687574.

Sheffi, Y. and J. B. Rice Jr. 2005. A supply chain view of the resilient enterprise. MIT Sloan Management Review 47(1), 41-48.

Stasik, A. and D. Jemielniak. 2021. Public involvement in risk governance in the internet era: impact of new rules of building trust and credibility. Journal of Risk Research, 1-17. doi: 10.1080/13669877.2020.1864008.

Steed, J. C. 2000. Engineering project risk management. Engineering Management Journal 10(1), 43. doi: 10.1049/em:20000112.

Tchangani, A. P. 2015. BOCR analysis: A framework for forming portfolio of developing projects. In M. Al-Shammari and H. Masri (Eds.), Multiple Criteria Decision Making in Finance, Insurance and Investment, Multiple Criteria Decision Making, pp. 189-204. Springer International Publishing. doi: 10.1007/978-3-319-21158-9\_9.

Teger, A. I., D. G. Pruitt, R. St. Jean, and G. A. Haaland. 1970. A reexamination of the familiarization hypothesis in group risk taking. Journal of Experimental Social Psychology 6(3), 346-350. doi: 10.1016/0022-1031(70)90068-5.

Tulasi, Ch. L. and A. R. Rao. 2015. Resource allocation in project scheduling application of fuzzy ahp. In Proceedings of the International Conference on Technology Business Management, pp. 512-521. 
Ullah, A., M. Pirzada, S. Jahan, H. Ullah, N. Turi, W. Ullah, M. F. Siddiqui, M. Zakria, K. Z. Lodhi, and M. M. Khan. 2018. Impact of low-dose chronic exposure to bisphenol a and its analogue bisphenol b, bisphenol $\mathrm{f}$ and bisphenol s on hypothalamo-pituitary-testicular activities in adult rats: A focus on the possible hormonal mode of action. Food and Chemical Toxicology 121, 24-36.

Vafaei, N., R. A. Ribeiro, and L. M. Camarinha-Matos. 2016. Normalization techniques for multi-criteria decision making: analytical hierarchy process case study. In Doctoral Conference on Computing, Electrical and Industrial Systems, pp. 261-269. Springer.

Vamvakas, P., E. E. Tsiropoulou, and S. Papavassiliou. 2019. Risk-aware resource management in public safety networks. Sensors 19(18), 3853. doi:10.3390/s19183853.

Vandenberg, L. N., R. Hauser, M. Marcus, N. Olea, and W. V. Welshons. 2007. Human exposure to bisphenol a (bpa). Reproductive Toxicology 24(2), 139-177.

Waddock, S., G. M. Meszoely, S. Waddell, and D. Dentoni. 2015. The complexity of wicked problems in large scale change. Journal of Organizational Change Management 28(6), 993-1012. doi:10.1108/jocm08-2014-0146.

Wang, D. and W. H. Ip. 2009. Evaluation and analysis of logistic network resilience with application to aircraft servicing. IEEE Systems Journal 3(2), 166-173.

Ward, Stephen and Chris Chapman. 2008. Stakeholders and uncertainty management in projects. Construction Management and Economics 26(6), 563-577. doi:10.1080/01446190801998708.

Weber, R. H. 2010. Internet of things - new security and privacy challenges. Computer Law and Security Review 26(1), 23-30.

Wijnmalen, D. J. D. 2007. Analysis of benefits, opportunities, costs, and risks BOCR with the AHP,ANP: A critical validation. Mathematical and Computer Modelling 46(7), 892-905. doi: 10.1016/j.mcm.2007.03.020.

Winston, A. 2014. Resilience in a hotter world. Harvard Business Review 92(4), 56-64.

Wiratanaya, G. N., D. P. Darmawan, L. M. Kolopaking, and W. Windia. 2015. Selection of beef production systems in bali: An analytical network with bocr approach. Journal of Economics and Sustainable Development 6(2), 45-59.

Zhou, J., X.-H. Chen, S.-D. Pan, J.-L. Wang, Y.-B. Zheng, J.-J. Xu, Y.-G. Zhao, Z.-X. Cai, and M.-C. Jin. 2019. Contamination status of bisphenol a and its analogues (bisphenol s, $f$ and $b$ ) in foodstuffs and the implications for dietary exposure on adult residents in zhejiang province. Food Chemistry 294, 160-170. 
